\title{
Obituary: B. S. Rhee (June 25, 1932-December 4, 2020)
}

\author{
S. K. Ryu ${ }^{1}$
}

Accepted: 4 January 2021 / Published online: 9 February 2021

c) Korean Carbon Society 2021

We are saddened to report the death of B. S. Rhee. He passed away suddenly on December, 4, 2020, while sleeping at the age of 88. He was the first and foremost researcher in the field of carbon materials in Korea. He graduated in 1958 with a M. S. at Yonsei University, Seoul, working as an instructor, and in 1963 became an assistant professor at Chungnam National University, Daejeon. In 1967, he took educational leave to study abroad at the Institute for Chemical Technology at the Universitat Karlsruhe, in Germany. He earned his Ph. D. in 1970 under the supervision of Prof. Erich Fitzer, internationally renowned in the field of carbon materials. The title of his dissertation was "Pyrokohlenstoff-Spiral-und Whiskerwachstum und Eigenschafte". After returning to Korea, he continuously collaborated with Professor Fitzer with the support of the Korea-German international projects. He was the only one and only carbon researcher in Korea before I joined his research project in 1982.

In the early 1980's, carbon fibers and new carbon materials gained global attention, and large Korean industries became interested in his research results. Eventually, in 1983, the SK group and KIMM (Korea Institute of Machinery \& Materials) cooperatively signed a large contract with Professor Rhee titled 'Industrialization of Carbon Fiber Development Technique'. This was the first step in developing carbon fibers in Korea. Shortly afterwards, he twice received a UNDP research grant for the 'Development of Carbon fiber from Pitch and Carbon Fiber Reinforced Composites' (1986-1987, 1990-1991). During this time, many well-known experts in the field of carbon materials, such as Prof. Fitzer (Germany), Dr. Ehrburger (France), Prof. Edie (USA), Prof. Mocha (Japan) and others, were invited to his laboratory to assist in his research. He and many experts contributed greatly to advance carbon research in Korea.

Prof. Rhee was extremely diligent. During his stay in Karlsruhe, each day he was the first researcher to turn on

$\triangle$ S. K. Ryu

skryu@cnu.ac.kr

1 Department of Chemical Engineering, Chungnam National University, Daejeon 34134, South Korea and the last to turn off the laboratory light. Once Prof. Fitzer told me "Mr. Rhee is really a mystery". His diligent character was inborn. At Chungnam University, he always arrived at the laboratory first and left the laboratory after 11 p.m. Sometimes he went to the laboratory on Sunday-until the late 1970's, when economic conditions were not good in Korea. University professors use the university commuter bus to go to school and return home. Prof. Rhee should have bought a car to return home from laboratory after 11 p.m. After I joined his research team, I also had to share this uncomfortable daily life. I had to go to the laboratory very early morning, eat pizza at lunch and dinner with him, and return home after 11 p.m. Prof. Rhee's favorite food was pizza. Sometimes I suggested that he eat another food, but his feet always took him to the pizza house. Once, I asked him why he returned home after 11 p.m. He answered that he didn't like listening to Mrs. Rhee's nagging about why he worked such long hours. If he returned home late, Mrs. Rhee would be sleeping. During these days, I also had to see my children sleeping.

For me, it was very hard to endure his unique lifestyle and frugal mind. On the other hand, I learned to appreciate his research philosophy that research is not hard work if you are passionate about it. He published many excellent papers and trained many students. The present chairman of the Korean Carbon Society, D. H. Jeong, and next chairman, Y. S. Lee, are both former Ph. D. students of Professor Rhee. After he retired from the university in 1996, he continued to go to the university and conduct research in my laboratory. He continued his research even after I retired university in 2011 until he passed away this December.

His precious contributions in carbon materials research will remain eternally in Korea. Now Professor Rhee has gone to heaven, and I worry that he may bother God with his hard work.

Publisher's Note Springer Nature remains neutral with regard to jurisdictional claims in published maps and institutional affiliations. 